\title{
Experimental exposure to propylene glycol mist in aviation emergency training: acute ocular and respiratory effects
}

\author{
G Wieslander, D Norbäck, T Lindgren
}

\begin{abstract}
Objectives-Propylene glycol (PG) (1-2 propanediol; CAS No 57-55-6) is a low toxicity compound widely used as a food additive, in pharmaceutical preparations, in cosmetics, and in the workplace-for example, water based paints, de-icing fluids, and cooling liquids. Exposure to PG mist may occur from smoke generators in discotheques, theatres, and aviation emergency training. Propylene glycol may cause contact allergy, but there is sparse information on health effects from occupational exposure to PG.
\end{abstract}

Methods-Non-asthmatic volunteers $(n=27)$ were exposed in an aircraft simulator to PG mist over 1 minute, during realistic training conditions. Geometric mean concentration of PG was $309 \mathrm{mg} / \mathrm{m}^{3}$ (range 176-851 $\mathrm{mg} / \mathrm{m}^{3}$ ), with the highest concentrations in the afternoon. The medical investigation was performed both before and after the exposure (within $15 \mathrm{~min}-$ utes). It included an estimate of tear film stability break up time, nasal patency by acoustic rhinometry, dynamic spirometry, and a doctor's administered questionnaire on symptoms.

Results-After exposure to PG mist for 1 minute tear film stability decreased, ocular and throat symptoms increased, forced expiratory volume in 1 second/forced vital capacity $\left(\mathrm{FEV}_{1} / \mathrm{FVC}\right)$ was slightly reduced, and self rated severity of dyspnoea was slightly increased. No effect was found for nasal patency, vital capacity (VC), FVC, nasal symptoms, dermal symptoms, smell of solvent, or any systemic symptoms. Those exposed to the higher concentrations in the afternoon had a more pronounced increase of throat symptoms, and a more pronounced decrease of tear film stability. In four subjects who reported development of irritative cough during exposure to PG, $\mathrm{FEV}_{1}$ was decreased by $5 \%$, but $\mathrm{FEV}_{1}$ was unchanged among those who did not develop a cough. Those who developed a cough also had an increased perception of mild dyspnoea.

Conclusion-Short exposure to PG mist from artificial smoke generators may cause acute ocular and upper airway irritation in non-asthmatic subjects. A few may also react with cough and slight airway obstruction.

(Occup Environ Med 2001;58:649-655)
Keywords: acoustic rhinometry; aviation medicine; propylene glycol; respiratory symptoms; tear film stability break up time

Main messages

- Propylene glycol is is a low toxicity compound widely used in many products.

- The concentration of propylene glycol mist in aviation emergency training can be high compared with other occupational exposure to this compound.

- Mist from artificial smoke generators may cause ocular and upper airway irritation in non-asthmatic subjects.

- A few may also react with cough and slight airway obstruction.

Policy implications

- Awareness should be spread that exposure to high concentrations of propylene glycol in workplaces and public places may cause ocular and respiratory irritation, and that sensitive subjects should be protected or avoid extreme or prolonged exposure.

Propylene glycol (PG) (1-2 propanediol; CAS $\mathrm{nr}$ 57-55-6) is a widely used compound because of its low toxicity ${ }^{1}$ and lack of carcinogenic or mutagenic effects. ${ }^{2}{ }^{3}$ It is used as a food additive, ${ }^{4}$ in pharmaceutical preparations, ${ }^{5}$ and in cosmetics. ${ }^{3}$ Rarely, allergic contact sensitisation to PG in consumer products may occur, ${ }^{6-8}$ and one case of systemic skin reactions in a PG sensitised subject after ingestion of food containing PG has been reported. ${ }^{9}$ Also skin irritation from PG in tooth paste ${ }^{10}$ as well as nasal and throat irritation related to PG in nasal spray has been reported. ${ }^{11}{ }^{12}$ Transdermal adsorption of PG may occur. ${ }^{13}$ There are a few case reports on severe systemic reactions from PG in humans, including one case of coma in a premature infant ${ }^{14}$ and two cases of acute renal tubular cell injury from pharmaceuticals disolved in PG. ${ }^{15}{ }^{16}$ The premature infant went into coma after treatment for burns with antiseptic dressings containing unusually high concentrations of PG. Ending the topical treatment resulted in complete recovery. ${ }^{14}$

Propylene glycol is metabolised to lactic acid and pyromaleic acid, normal intermediates in human metabolism, either by oxidisation or phosphatisation. ${ }^{4}$ Metabolic formation of PG and 2,3-butanediol has been reported in 
alcoholic subjects, both in the presence and absence of alcohol, ${ }^{17}$ in premature infants, ${ }^{17}$ in diabetic patients, ${ }^{17}$ and with specific enzyme deficiencies (congenital propionic and methylmalonic acidaemia). Also, alcohol related diols (PG and 2,3-butanediol) have been shown to cause insulin resistance in rats. ${ }^{18}$

Occupational exposure to PG may occur in many occupational settings. The phasing out of organic solvents at work has increased the use of PG in Sweden, as it is commonly used in many water based products-such as water based paints. ${ }^{19-22}$ The annual Swedish consumption ( 8 million inhabitants) of PG is between 13200 and 13300 tonnes, and it is used in 1183 products. It is the 17 th most common chemical counted as number of products in which it is used. ${ }^{19}$ Other sources of occupational exposures include aircraft deicing work, where both ethylene glycol $^{23}$ and PG are used, ${ }^{23}$ and exposure to glycol based cooling liquids in car engines. ${ }^{24}$

Also, PG is commonly used in artificial smoke generators in discotheques, theatres, and emergency training. In connection with use of smoke generators in aviation emergency training, being a part of the basic education of pilots and flight attendants at Scandinavian Airline Systems (SAS), concern was raised about possible respiratory effects from this exposure

There is sparse published information on irritative or respiratory effects of PG in humans. ${ }^{25}$ Recently, clinical methods that can be applied in exposure studies have become available, including measurement of tear film stability break up time, ${ }^{26}{ }^{27}$ and nasal patency by acoustic rhinometry. ${ }^{28-30}$ These methods have been applied to study transient physiological effects at controlled exposures to volatile organic compounds. Decreased nasal patency has been reported at exposure to a mixture $\left(4 \mathrm{~h} ; 10 \mathrm{mg} / \mathrm{m}^{3}\right)$ of 22 different volatile organic compounds, not including PG. $^{31}$ In another experimental study, exposure to a mixture of PG and three glycol ethers induced ocular symptoms, but did not affect tear film stability, nasal patency, or lung function. ${ }^{32}$

The aim of the investigation was to study effects of an experimental exposure to PG mist, at exposure levels occurring during normal aviation emergency training. The physiological effects studied included tear film stability, nasal patency, and lung function, as well as subjective symptoms. The study was approved by the ethics committee of the Medical Faculty of Uppsala University.

\section{Material and methods}

STUDY POPULATION

Healthy non-asthmatic volunteers $(n=27), 22$ men and five women, were examined medically before and after exposure to PG mist. Most were pilots working in civil aviation. Mean (SD) age of the group was 44 (11) years, 22\% were current smokers, $44 \%$ were ex-smokers. In total, $30 \%$ had a history of atopy, $15 \%$ had hay fever, $15 \%$ had a history of childhood eczema, but none reported allergy to furry animals. In total, two women and six men had a history of atopy, whereas three women and 16 men did not have atopy, a non-significant but numerically higher occurrence of atopy among the women. None had ever had any respiratory disorders, including asthma or chronic bronchitis diagnosed by a doctor, and none had any febrile respiratory infection the week before the investigation. The subjects were naive, in that none had previous occupational exposure to PG. The investigations were done at normal aviation emergency training, during 1 week in March 1998, before the pollen season had started in mid-Sweden. The flight simulator belonged to a training centre of the flight academy of the Scandinavian Airline System (SAS). The artificial smoke generator was placed in the flight simulator, with a commercial PG solution for smoke generation. The exposure was performed as a part of the regular training schedules for pilots, aiming to train pilots for evacuation at fire emergency situations.

ASSESSMENT OF PERSONAL FACTORS

One general medical questionnaire was used to gather information on personal factors, including medical disorders, medication, occupational data, the home environment, and smoking habits. ${ }^{28-30}$ Atopy was defined as having a history of childhood eczema or current history of allergy related to exposure to common IgE mediated allergens in Sweden (tree pollen, grass pollen, or furry animals). Current smoker was defined as reporting actual smoking in the interview (>1 cigarette/day), or stopping smoking less than 1 year ago.

INFORMATION ON CURRENT SYMPTOMS

Information on current symptoms was obtained from two questionnaires used in previous investigations. The first questionnaire contained 10 rating scales on current ocular, nasal, throat symptoms, dyspnoea, malodour, and systemic symptoms. ${ }^{33}$ Answers were given on a $100 \mathrm{~mm}$ visual analogue rating scale (VASscale) adapted from Kjellberg et al, ${ }^{34}$ graded from "not at all" to "almost unbearable". The second questionnaire contained 23 yes or no questions on different types of ocular, respiratory, and dermal symptoms, as well as systemic symptoms-for example, headache, nausea, and fatigue. ${ }^{30}$ Both questionnaires were administered before and after the exposure to PG.

ASSESSMENT OF TEAR FILM STABILITY

Tear film stability was estimated by a standardised method, self reported tear film stability break up time measuring the time the subject could keep the eyes open without pain, when watching a fixed point at the wall. The method is mentioned in our introduction as tear film stability and has been used previously. It has been shown to correlate well with the fluoresceine method for detection of tear film stability. ${ }^{26}{ }^{27}$ Moreover, it has been shown that tear film stability is lower in subjects reporting ocular symptoms. ${ }^{28}$

ACOUSTIC RHINOMETRY

Acoustic rhinometry (Rhin 2000; wideband noise; continuously transmitted) was applied to 


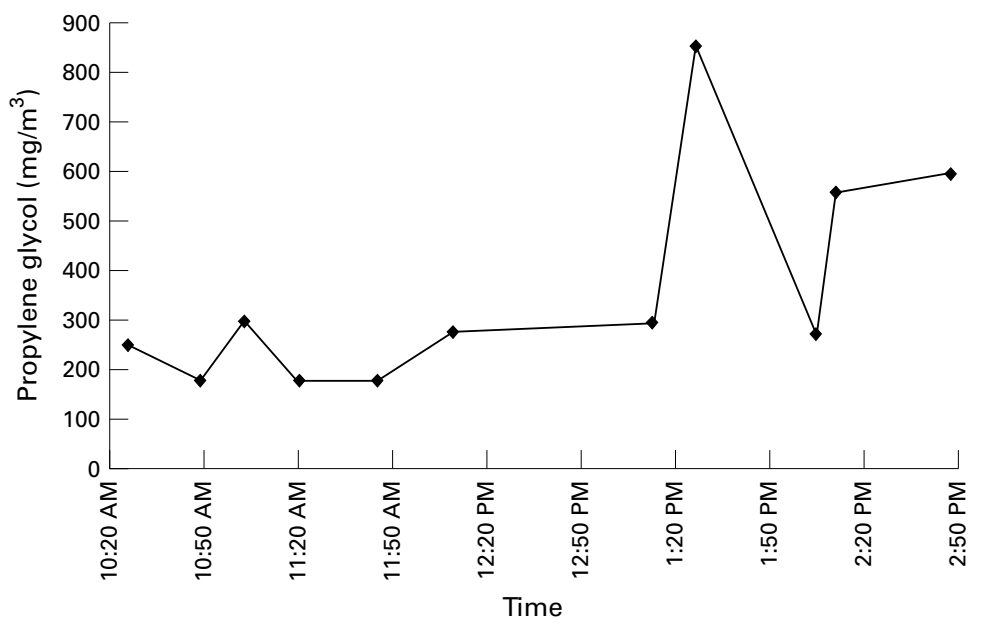

Air concentration of propylene glycol at aviation emergency training (1 minute point measurements), as a function of time of the day.

Table 1 Average ratings on 10 questions ${ }^{*}$ on smell before and after 1 minute of exposure to propylene glycol mist $(n=27)$

\begin{tabular}{|c|c|c|c|}
\hline Type of rating & $\begin{array}{l}10 \text { min before } \\
\text { exposure mean } \\
(S D)\end{array}$ & $\begin{array}{l}10 \text { min after } \\
\text { exposure } \\
\text { mean }(S D)\end{array}$ & $\begin{array}{l}\text { Two } \\
\text { tailed } p \\
\text { valuet }\end{array}$ \\
\hline Ocular irritation & $5(10)$ & $14(13)$ & $<0.001$ \\
\hline Nasal irritation & $7(10)$ & $10(11)$ & 0.17 \\
\hline Throat irritation & $7(9)$ & $20(14)$ & $<0.001$ \\
\hline $\begin{array}{l}\text { Difficulty in } \\
\text { breathing }\end{array}$ & $3(4)$ & $7(10)$ & 0.048 \\
\hline Solvent smell & $3(6)$ & $4(7)$ & 0.43 \\
\hline Headache & $4(6)$ & $4(6)$ & 0.46 \\
\hline Fatigue & $6(10)$ & $5(8)$ & 0.40 \\
\hline Nausea & $3(3)$ & $2(3)$ & 0.33 \\
\hline Dizziness & $2(3)$ & $5(7)$ & 0.10 \\
\hline Intoxication & $2(3)$ & $4(6)$ & 0.24 \\
\hline
\end{tabular}

†Calculated by Students $t$ test for paired comparison.

measure nasal patency. The measurements were made under standardised forms (sitting), after 5 minutes of rest. By means of acoustic reflection the minimum cross sectional areas (MCAs) on each side of the nose were measured from 0 and $22 \mathrm{~mm}$ (MCA1) and from 23 and $54 \mathrm{~mm}$ (MCA2) from the nasal opening. The volumes of the nasal cavity on the right and the left sides were also measured from 0 and $22 \mathrm{~mm}$ (VOL1) and from 23 to $54 \mathrm{~mm}$ (VOL2). The mean values were calculated from three subsequent measurements on each side of the nose. Data on nasal dimensions in the present study are presented as the sum of the values recorded for the right side and the left side.

\section{LUNG FUNCTION TESTS}

Respiratory function was studied by dynamic spirometry. Vital capacity (VC), forced vital capacity (FVC), peak expiratory flow (PEF), and forced expiratory flow in 1 second $\left(\mathrm{FEV}_{1}\right)$ were measured with a Vitalograph (Vitalograph, Buckingham, England) which was calibrated daily. Also, $\mathrm{FEV}_{1} / \mathrm{FVC}$ was calculated. All the tests were carried out in a standardised way with the same spirometer, by a trained nurse. To avoid disturbance of nasal patency, a nose clip was not used. The measurements were performed three times on each subject, and the highest values were noted. A test was considered adequate when the deviation between the two best tests were less than $5 \%$. The results were expressed as a percentage of normal values based on standardisation to age, sex, height, smoking habits, and body mass using reference values from Uppsala. $^{35}$

TEST SEQUENCE

All physiological measurements and questionnaires were administered by a physician, in a modern office building, with a general ban on smoking indoors. Moreover, smokers were not allowed to smoke during the test period, which started 15 minutes before the exposure, when the subject was asked to sit down. During this time, the tear film stability test was performed first, then the two symptom questionnaires. After about 5 minutes, acoustic rhinometry was performed, then the dynamic spirometry. Then the subjects entered the smoke training unit, were exposed to PG mist for 1 minute, and went out to sit down and wait for repeated medical investigation. The same test sequence was applied before and after the exposure to PG, and was completed within 15 minutes of the exposure. When all testing was finished, the general medical questionnaire was answered. The tests were performed during 2 days from 0930 to 1500 , with a lunch break from 1200 to 1300.

\section{ASSESSMENT OF EXPOSURE}

Room temperature and relative air humidity was measured by an Assman psychrometer. Propylene glycol in the flight simulator was sampled by pumped sampling, on a synthetic polymer tube (XAD-7; SKC 226-95, SKC, USA). The sampling time was 1 minute, and the sampling rate was $200 \mathrm{ml} / \mathrm{min}$. The XAD-7 tube was desorbed with $1 \mathrm{ml}$ of methylene chloride, and analysed for PG, with a method described already. ${ }^{36}$ A recovery of $100 \%$ of PG on the XAD tube was assumed, as was demonstrated for higher concentrations of PG in earlier desorbtion efficiency tests. ${ }^{36}$ To control for possible overloading of the sorbent tubes by PG, both the measuring layer and the control layer of the tubes were analysed. As it was a possibility that particulate PG mist could be adsorbed on the glass wool plug in the inlet of the sampling tubes, the glass wool was desorbed separately with another $1 \mathrm{ml}$ of methylene chloride.

Exposure to formaldehyde in the flight simulator was measured by pumped sampling on glass fibre filters impregnated with 2,4dinitrophenyl hydrazine $(2,4-\mathrm{DNF})$, at a flow rate of $200 \mathrm{ml} / \mathrm{min}$ for 4 hours. ${ }^{37}$ The filters were analysed by liquid chromatography. To detect other specific volatile organic compounds in the flight simulator, pumped sampling on a conventional charcoal sorbent tube (SKC 226-01) was performed (4 h; 200 $\mathrm{ml} / \mathrm{min}$ ). The charcoal tube was desorbed with $1 \mathrm{ml}$ carbon disulfide. Both PG and other specific compounds were analysed by means of a Hewlett Packard 5890 gas chromatograph equipped with a mass selective detector (HP 5970) (GC-MS), using a 50 metre cross linked methyl silicone capillary column (HP-1, 
Table 2 Different types of symptoms * before and after 1 minute of exposure to propylene glycol mist $(n=27)$

\begin{tabular}{|c|c|c|c|c|c|c|}
\hline \multirow[b]{2}{*}{ Type of symptoms } & \multicolumn{2}{|c|}{$\begin{array}{l}\text { Symptoms } 10 \mathrm{~min} \\
\text { before exposure }\end{array}$} & \multicolumn{2}{|c|}{$\begin{array}{l}\text { Symptoms } 10 \mathrm{~min} \\
\text { after exposure }\end{array}$} & \multicolumn{2}{|c|}{$\begin{array}{l}\text { Proportion developing } \\
\text { a particular symptomt }\end{array}$} \\
\hline & $n$ & $(\%)$ & $n$ & $(\%)$ & $n$ & $(\%)$ \\
\hline Sore eyes & 1 & 4 & 6 & 22 & $5 / 26$ & 19 \\
\hline Itching in the eyes & 1 & 4 & 4 & 15 & $3 / 26$ & 12 \\
\hline Dry eyes & 1 & 4 & 9 & 33 & $8 / 26$ & 31 \\
\hline Gritty eyes & 2 & 7 & 3 & 11 & $1 / 25$ & 4 \\
\hline Eye redness & 0 & 0 & 0 & 0 & $0 / 27$ & 0 \\
\hline Swollen eyelids & 0 & 0 & 0 & 0 & $0 / 27$ & 0 \\
\hline At least one ocular symptom & 2 & 7 & 11 & 41 & $9 / 25$ & 36 \\
\hline Nasal catarrh & 1 & 4 & 2 & 7 & $1 / 26$ & 4 \\
\hline Nasal itch & 0 & 0 & 2 & 7 & $2 / 27$ & 7 \\
\hline Sneezing & 0 & 0 & 0 & 0 & $0 / 27$ & 0 \\
\hline Nasal obstruction & 1 & 4 & 1 & 4 & $0 / 26$ & 0 \\
\hline At least one nasal symptom & 2 & 7 & 3 & 11 & $1 / 25$ & 4 \\
\hline Throat dryness & 4 & 15 & 17 & 63 & $14 / 23$ & 61 \\
\hline Sore throat & 1 & 4 & 1 & 4 & $0 / 26$ & 0 \\
\hline At least one throat symptom & 4 & 15 & 18 & 67 & $14 / 22$ & 64 \\
\hline Irritative cough & 2 & 7 & 6 & 22 & $4 / 25$ & 16 \\
\hline Difficulties in breathing & 1 & 4 & 1 & 4 & $0 / 26$ & 0 \\
\hline $\begin{array}{l}\text { At least one lower } \\
\text { respiratory symptom }\end{array}$ & 2 & 7 & 6 & 22 & $4 / 25$ & 16 \\
\hline Sensation of catching a cold & 1 & 4 & 1 & 4 & $1 / 26$ & 4 \\
\hline Headache & 1 & 4 & 1 & 4 & $0 / 26$ & 0 \\
\hline Nausea & 0 & 0 & 0 & 0 & $0 / 27$ & 0 \\
\hline Fatigue & 1 & 4 & 1 & 4 & $1 / 26$ & 4 \\
\hline $\begin{array}{l}\text { At least one general } \\
\text { symptom }\end{array}$ & 2 & 7 & 2 & 7 & $0 / 25$ & 0 \\
\hline Facial itching & 0 & 0 & 0 & 0 & $0 / 27$ & 0 \\
\hline Facial rash & 1 & 4 & 0 & 0 & $0 / 26$ & 0 \\
\hline Itching on the hands & 0 & 0 & 1 & 4 & $1 / 27$ & 4 \\
\hline Rashes on the hands & 2 & 7 & 2 & 7 & $0 / 25$ & 0 \\
\hline Eczema & 2 & 7 & 2 & 7 & $0 / 25$ & 0 \\
\hline $\begin{array}{l}\text { At least one dermal } \\
\text { symptom }\end{array}$ & 4 & 15 & 3 & 11 & $0 / 23$ & 0 \\
\hline
\end{tabular}

*Yes/no questions from a detailed symptom questionnaire (Wålinder et $\mathrm{l}^{29}$ ).

†Calculated for those not reporting the particular symptom before the exposure.

Table 3 Rhinometric measurements before and after 1 minute of exposure to propylene glycol mist $(n=27)$

\begin{tabular}{llll}
\hline $\begin{array}{l}\text { Rhinometric } \\
\text { parameter }\end{array}$ & $\begin{array}{l}\text { 10 min before } \\
\text { exposure mean } \\
(S D)\end{array}$ & $\begin{array}{l}\text { 10 min after } \\
\text { exposure mean } \\
(S D)\end{array}$ & $\begin{array}{l}\text { Two tailed } \\
\text { p value }\end{array}$ \\
\hline MCA1 $\left(\mathrm{cm}^{2}\right)$ & $1.31(0.20)$ & $1.32(0.32)$ & 0.40 \\
MCA2 $\left(\mathrm{cm}^{2}\right)$ & $1.43(0.36)$ & $1.37(0.32)$ & 0.36 \\
VOL1 $\left(\mathrm{cm}^{3}\right)$ & $4.44(0.73)$ & $4.36(1.05)$ & 0.33 \\
VOL2 $\left(\mathrm{cm}^{3}\right)$ & $8.35(2.01)$ & $7.90(1.81)$ & 0.36 \\
\hline
\end{tabular}

${ }^{\star}$ Calculated by Student's $t$ test for paired comparison.

Table 4 Dynamic spirometry values before and after 1 minute of exposure to propylene glycol mist $(n=27)$

\begin{tabular}{lccl}
\hline $\begin{array}{l}\text { Lung function } \\
\text { parameter }\end{array}$ & $\begin{array}{l}\text { 10 min before } \\
\text { exposure mean } \\
\text { (SD) }\end{array}$ & $\begin{array}{l}10 \text { min after } \\
\text { exposure mean } \\
(S D)\end{array}$ & $\begin{array}{l}\text { Two tailed } \\
\text { p value }\end{array}$ \\
\hline VC & $4.92(0.93)$ & $4.92(0.91)$ & 0.48 \\
FVC & $4.66(0.89)$ & $4.70(0.96)$ & 0.23 \\
FEV $_{1}$ & $4.01(0.71)$ & $3.98(0.78)$ & 0.29 \\
FEV $_{1} /$ FVC & $86.8(7.3)$ & $84.8(6.5)$ & 0.049 \\
PEF & $650(179)$ & $638(183)$ & 0.45 \\
\hline
\end{tabular}

*Calculated by Student's $t$ test for paired comparison.

Hewlett Packard) with an inner diameter of $0.32 \mathrm{~mm}$ and a film thickness of $1 \mu \mathrm{m}$. The oven temperature was programmed for an initial hold for 5 minutes at $35^{\circ} \mathrm{C}$ after which the temperature increased to $200^{\circ} \mathrm{C}$ at a rate of $15^{\circ} \mathrm{C} / \mathrm{min}$. Carrier gas (helium) flow rate was 1 $\mathrm{ml} / \mathrm{min}$. For each substance, a mass spectrum and retention time was assessed. ${ }^{36}$

STATISTICAL ANALYSIS

Differences in VAS scales, nasal patency, and lung function before and after exposure to PG were analysed by Student's $t$ test for paired comparisons. As the tear film stability was not normally distributed, change in tear film stability was analysed by Wilcoxon matched pairs signed rank test. Changes in symptoms, measured as a dichotomous outcome variable, were measured by the McNemar test.

\section{Results}

EXPOSURE MEASUREMENTS

Room temperature was $22.0^{\circ} \mathrm{C}-22.5^{\circ} \mathrm{C}$, and mean relative air humidity in the flight simulator was $34 \%$. Eleven 1 minute measurements of PG were performed. The geometric mean concentration of $P G$ in the flight simulator was $309 \mathrm{mg} / \mathrm{m}^{3}(\mathrm{GSD}=1.7)$. Arithmetic mean concentration of PG was $360 \mathrm{mg} / \mathrm{m}^{3}$ (range 176-851 $\mathrm{mg} / \mathrm{m}^{3}$ ), with an arithmetic mean exposure of $220 \mathrm{mg} / \mathrm{m}^{3}$ in the morning, and $520 \mathrm{mg} / \mathrm{m}^{3}$ in the afternoon. The distribution of the 11 point measurements over the day can be seen in figure 1. Most detected PG was in the measuring layer of the sampling tube, only $5 \%-10 \%$ was detected in the control layer, and $<1 \%$ was found in the glass wool plug in the inlet of the tube. Low concentrations of formaldehyde were detected in the flight simulator $\left(29 \mu \mathrm{g} / \mathrm{m}^{3}\right)$, but no other volatile organic compounds.

\section{SYMPTOMS}

The most common annoyance after the exposure were ocular and throat irritation as measured by the VAS scales (table 1). When analysing changes of VAS ratings, a significant increase of ocular irritation $(\mathrm{p}<0.001)$, throat irritation $(p<0.001)$, and dyspnoea $(p=0.048)$ was found, but there were no effects on solvent smell or other symptoms.

The most common symptoms were a sensation of sore and dry eyes, throat dryness, and irritative cough, as measured by the more detailed symptom questionnaire, requesting a yes or no answer (table 2). When grouping the symptoms for different organs, a significant increase was found for ocular $(p=0.005)$ and throat symptoms $(p<0.001)$. Nine subjects without previous symtoms (36\%) developed at least one ocular symptom after exposure to PG, and 14 (64\%) developed throat symptoms. Two reported appearance of nasal catharr and one got nasal itching, but none reported sneezing or nasal obstruction after the exposure. None reported appearance of headache, nausea, or breathing difficulties after exposure to PG, and there was no net change in reporting of fatigue. One subject reported the appearance of itching on the hands, and another reported disappearance of facial skin rash after the exposure to PG mist.

There were some indications that women and those with a history of atopy seemed to be more sensitive to exposure to PG, for some types of symptoms, but the number of women $(n=5)$ and subjects with atopy $(n=8)$ were small. In total, $29 \%$ of men and $80 \%$ of women reported the development of throat symptoms, but there were no sex difference for development of ocular symptoms. Moreover, $50 \%$ of those with atopy, and $11 \%$ of those without 
Table 5 Changest of symptom ratings and physiological measurements stratified for different levels of exposure

\begin{tabular}{|c|c|c|}
\hline & $\begin{array}{l}\text { Morning test (lower } \\
\text { exposure) }(n=18) \\
\text { mean }(S D)\end{array}$ & $\begin{array}{l}\text { Afternoon test } \\
\text { (higher exposure) } \\
(n=9) \text { mean (SD) }\end{array}$ \\
\hline \multicolumn{3}{|l|}{ VAS scales: } \\
\hline Change in ocular symptom rating (\%) & $9(12)^{\star \star}$ & $8(11)$ \\
\hline Change in nasal symptoms rating (\%) & $1(10)$ & $8(14)$ \\
\hline Change in throat symptoms rating (\%) & $11(17)^{\star \star}$ & $18(15)^{\star \star \star}$ \\
\hline Change in rating of dyspnoea $(\%)$ & $3(9)$ & $7(14)$ \\
\hline \multicolumn{3}{|l|}{ Physiological measurements: } \\
\hline Change in tear film stability (break up time) & $-6(24)$ & $-13(28)^{\star}$ \\
\hline Change in MCA $1\left(\mathrm{~cm}^{2}\right)$ & $-0.01(0.22)$ & $0.06(0.34)$ \\
\hline Change in MCA2 $\left(\mathrm{cm}^{2}\right)$ & $-0.08(0.30)$ & $-0.02(0.40)$ \\
\hline Change in VOL1 $\left(\mathrm{cm}^{3}\right)$ & $-0.10(0.90)$ & $-0.04(0.89)$ \\
\hline Change in VOL2 $\left(\mathrm{cm}^{3}\right)$ & $-0.51(2.21)$ & $-0.31(2.80)$ \\
\hline Change in $\mathrm{FEV}_{1}$ ( $\%$ of predicted value) & $-1(6)$ & $-1(10)$ \\
\hline
\end{tabular}

${ }^{\star} \mathrm{p}<0.05 ;{ }^{\star \star} \mathrm{p}<0.01 ;{ }^{\star \star \star} \mathrm{p}<0.001$, change after the exposure (Student's $t$ test for paired comparisons). †Calculated as difference between values after and before exposure.

atopy reported development of least one ocular symptom. Finally, $100 \%$ of those with atopy, but only $28 \%$ of those without atopy reported development of throat symptoms after exposure to PG.

PHYSIOLOGICAL INVESTIGATIONS

All participated in the acoustic rhinometry and the lung function test. One could not participate in the measurement of tear film stability due to nervous blinking. A significant decrease of tear film stability was found after exposure to PG, with a reduction of mean tear film stability break up time from 38 to 29 seconds $(p=0.02)$, and the decrease of tear film stability was similar in men and women. The difference in tear film stability before and after the exposure was the same (mean decrease $6 \mathrm{~s}$ ) in those who developed and those who did not develop ocular symptoms. When comparing tear film stability after the exposure, however, those who developed ocular symptoms had numerically lower tear film stability (mean $27 \mathrm{~s}$ ) than those who did not (mean $34 \mathrm{~s}$ ). The two people with ocular symptoms before the exposure had the greatest decrease of tear film stability (mean decrease $38 \mathrm{~s}$ ).

No significant changes in any measures of nasal patency were found after exposure to PG (table 3). Most of the lung function values remained unchanged after exposure to $P G$, but there was a minor numerical decrease of $\mathrm{FEV}_{1}$ from $103 \%$ to $102 \%$ at exposure, and a small but significant decrease of $\mathrm{FEV}_{1} / \mathrm{FVC}$ $(p=0.049)$. Mean VC was unchanged after the exposure, whereas FVC was slightly increased (table 4). None of the 27 participants had an initial lung function value $\left(\mathrm{FEV}_{1}\right)$ below $80 \%$ of predicted value, but one got a $77 \%$ value for $\mathrm{FEV}_{1}$ after the exposure. The mean decrease of $\mathrm{FEV}_{1}$ and $\mathrm{FEV}_{1} / \mathrm{FVC}$ was similar in subjects with and without a history of atopy. Moreover, there were no significant association between a decrease in $\mathrm{FEV}_{1}$, and development of mild dyspnoea (measured by the rating scales) in the total material

A few, however, reacted with cough, mild airway obstruction, and mild dyspnoea. There were four subjects $(16 \%)$ who developed irritative cough after the exposure. All were non-smoking men, without any history of allergies. They had an average reduction in $\mathrm{FEV}_{1}$ of $5 \%$, compared with a $0 \%$ reduction of
$\mathrm{FEV}_{1}$ among those who did not develop a cough. Moreover, those four subjects had an increase in self rated dyspnoea of $13 \%$ on the analogue scale, whereas those who did not develop cough only had a $1 \%$ increase of dyspnoea, a significant difference between the two groups $(\mathrm{p}<0.01)$.

DOSE-EFFECT RELATIONS

The investigation was not a controlled exposure chamber test, but a physiological investigation performed during exposure conditions occurring when PG mist was used in aviation training. The mean exposure measurements showed that there were higher exposures (520 $\left.\mathrm{mg} / \mathrm{m}^{3}\right)$ in the afternoon than in the morning, before the lunch break $\left(220 \mathrm{mg} / \mathrm{m}^{3}\right)$. These differences made it possible to evaluate possible dose-effect relations comparing changes from before to after exposure in those nine subjects exposed in the afternoon with those 18 exposed in the morning. A dose-effect relation was found for tear film break up time, with a 6 second average decrease in the low exposure group and a 13 second decrease in the high exposure group. Moreover, $47 \%$ in the low exposure group but $100 \%$ in the high exposure group reported development of throat dryness, and the rating of throat symptoms on the VAS scale were higher in the highly exposed group. By contrast, no dose-effect relations were found for ocular or nasal symtoms, dyspnoea, nasal patency, or $\mathrm{FEV}_{1} \%$ (table 5).

\section{Discussion}

The design was experimental and showed acute effects on ocular and throat symptoms, and decreased tear film stability in nonasthmatic subjects after 1 minute exposure to PG mist from an artificial smoke generator. A few reacted with a small lower airway obstruction, cough, and mild dyspnoea. Moreover, there were indications of a dose-effect relation for throat symptoms and impairment of tear film stablility. There were some indications that women and subjects with a history of atopy reported more of some types of symptoms after the exposure. These results agree with a population study, suggesting that women and subjects with atopy are more sensitive to emissions from indoor paint. ${ }^{38}$

The physiological methods in the chosen acute effect test battery have been used in previous epidemiological ${ }^{30}$ and experimental investigations. $^{31}$ As there were few subjects participating in this type of emergency training at each time, the number of participants was limited. The study was based on non-asthmatic volunteers, participating in the exposure as a part of their occupational training. The exposure time was short, but relevant to the exposure time used in aviation emergency training. Despite the limitations of the study, limited power, short exposure time, and exclusion of asthmatic people, we showed significant effects of airborne exposure to PG mist.

The exposure concentration of PG (geometric mean $309 \mathrm{mg} / \mathrm{m}^{3}$ ) was quite high, compared with other exposure measurements of this compound in work environments. Exposure 
measurements in house painters who used water based paints ${ }^{36}$ showed exposure concentrations of PG ranging from $<0.1$ to 12.7 $\mathrm{mg} / \mathrm{m}^{3}$ (mean $2.6 \mathrm{mg} / \mathrm{m}^{3}$ ), but no measurable exposure to PG was found in motor servicing work. ${ }^{24}$ The exposure measurements showed that the concentrations of other volatile organic compounds in the flight simulator were very low, and the concentration of formaldehyde was similar to that found in mid-Swedish dwellings. ${ }^{39}$

To our knowledge, this is the first study of irritative and respiratory effects of occupational exposure to airborne PG. There are some earlier exposure studies in animals. In one study, 19 rats were exposed by nose only inhalation to 0, 160 (low), 1000 (medium), and 2200 (high) $\mathrm{mg} / \mathrm{m}^{3}$ concentrations of $\mathrm{PG}, 6$ hours/day 5 days/week for 90 days. There was a significant increase in the number of goblet cells in the nasal passages of the medium and highly exposed animals. It was concluded that this exposure to PG caused nasal haemorrhage and ocular discharge in a high proportion of animals, possibly due to dehydration of the nares and eyes. ${ }^{40}$

In one study of the effects of organic solvents to induce erythema, no effect was found on dermal blood flow measured by Doppler flowmetry, after dermal application of concentrated PG in humans. ${ }^{41}$ In another study, children were exposed to airborne PG (mean concentration $69 \mathrm{mg} / \mathrm{m}^{3}$, maximum $94 \mathrm{mg} / \mathrm{m}^{3}$ ) at air sterilisation, continuously during several weeks. No negative effects were found on mucous membranes in the upper respiratory tract. ${ }^{42}$

There are some indications that PG in tooth paste and nasal spray may cause mucosal irritation in humans, but the relevance of these findings for occupational exposure to $P G$ is unclear. When comparing dermal irritation from four commercial toothpastes, three with PG and one without PG, less irritation was found for the toothpaste without PG. ${ }^{10}$ When comparing airway symptoms in subjects with allergic rhinitis who used two different nasal sprays, less nasal burring, stinging, and throat irritation was found when the concentration of PG was reduced in the newer formulation of nasal spray. ${ }^{12}$ Similar results were found in another study that showed improved nasal airflow, decrease of nasal eosinophilia, and less nasal burning and stinging with a new formulation of nasal spray containing less PG. ${ }^{11}$ Also, one recent case report describes asthma crisis and cough induced by PG. ${ }^{25}$

There are three experimental studies on acute effects of emissions from water based paints containing both PG and other volatile organic compounds-for example, glycol ethers. In one study, 30 non-asthmatic subjects were exposed for 4 hours to a mixture of PG $\left(10 \mathrm{mg} / \mathrm{m}^{3}\right)$, texanol (2,2,4-trimethyl $1,3-$ pentanediol monoisobutyrate) $\left(5 \mathrm{mg} / \mathrm{m}^{3}\right)$, diethylene glycol monobutyl ether $\left(5 \mathrm{mg} / \mathrm{m}^{3}\right)$, diethylene glycol monobutyl ether $\left(5 \mathrm{mg} / \mathrm{m}^{3}\right)$, and dipropylene glycol monomethyl ether (5 $\left.\mathrm{mg} / \mathrm{m}^{3}\right)$. Effects on ocular symptoms, but no effect on tear film stability, nasal patency measured by acoustic rhinometry, or lung function were found. ${ }^{32}$ In another study, 18 non-asthmatic subjects were exposed for 2 hours to emissions from two different formulations of water based paint, with emissions from viscosed water as a control. The exposure to PG was $0.13 \mathrm{mg} / \mathrm{m}^{3}$ with the old formulation, and $0.03 \mathrm{mg} / \mathrm{m}^{3}$ in the new formulation, expressed as toulene equivalents. The new formulation had a reduced emission of other volatile organic compounds, including 2-methyl-1propanol, 2-butoxy-ethanol, and diisobutyl glutarate. None of the two paint formulations had a significant effect on tear film stability, nasal patency measured by acoustic rhinometry, or concentration of biomarkers of inflammation in nasal lavage. The old paint formulation induced some acute symptoms, had more smell, and induced a minor acute airway obstruction, whereas the new paint had no such effects. ${ }^{43}$ Finally, 17 asthmatic subjects with previous exacerbation of symptoms on exposure to paint or other odours were exposed to emissions from two different formulations of water based paints. The new formulation, a volatile organic compound free paint, caused less wheeze and breathlessness, and less airway obstruction. ${ }^{44}$

Despite the common use of PG in many commercial and industrial products, there are few studies on irritative effects in humans from airborne exposure to this compound. As PG is commonly used in artificial smoke generators in discotheques, theatres, and emergency training, possible adverse effects of such exposure can be of public interest, particularly for sensitive subjects. Our measurements showed that exposure to PG can be high from smoke generators, higher than in other occupational applications. We conclude from our results that short exposures to PG mist from smoke generators may cause acute irritative ocular and upper airway effects in non-asthmatic subjects, and some symptoms were more common in women and subjects with atopy. A few may also react with minor lower airway obstruction, cough, and mild dyspnoea. Recent experimental studies have shown that there are subjects with with increased sensitivity to trigeminal irritants (sensory hyperreactivity). These subjects react with cough after provocation with capsaicin solutions, and the reaction can be blocked by lidocain, which inhibits nerve transmission in the sensory nerves. ${ }^{45}$ Moreover, such subjects may react with cough and asthma-like symptoms after provocation to irritants. ${ }^{46}$ Thus, sensory hyperreactivity could be one mechanism behind the development of a combination of cough, slight airway obstruction, and mild dyspnoea in a few of those exposed to PG mist. As exposure to PG mist may occur both in workplaces and certain public places, studies on respiratory effects of PG in subjects with obstructive respiratory disorders or sensory hyperreactivity seem relevant. This study was supported by grants from the Swedish Council
for Worklife Research, the Swedish Foundation for Health Care for Worklife Research, the Swedish Foundation for Health Care
Sciences and Allergy Research, and the Swedish Association Sciences and Allergy Resear
against Asthma and Allergy. 
1 Rowe VK, Wolf MA. Glycols (propylene glycol, $\mathrm{C}_{3} \mathrm{H}_{8} \mathrm{O}_{2}$ or $\mathrm{CH}_{3} \mathrm{CHOHCH} \mathrm{HH}_{2} \mathrm{OH}$ (1,2-Propenediol, Methyl ethylene glycol)) In: Patty, ed. Industrial hygiene and toxicology. New York, NY: Wiley, 1982;2:1515-18.

2 Anonymous. Reproductive toxicology. Propylene glycol. Environ Health Perspect 1997;105(suppl 1):231-2.

3 Anonymous. Final report on the safety assessment of propylene glycol and propylene glycols. $\mathcal{F}$ Am Coll Toxicol 1994;6:437-91.

4 Mortensen B. Health effects of selected chemicals 2 . Propylene glycol. Nord 1993;29:181-208

5 Glover ML, Reed MD. Propylene glycol: the safe diluent that continues to cause harm. Pharmacotherapy 1996;16: 690-3.

6 Gonzalo MA, de Argila D, Garcia JM, et al. Allergic contact dermatitis to propylene glycol. Allergy 1999;54:82-3.

7 Catanzaro JM, Smith JG Jr. Propylene glycol dermatitis: a review article f Am Acad Dermatol 1991;24:90-5.

8 Funk JO, Maibach HI. Propylene glycol dermatitis: re-evaluation of an old problem: a review article Contact re-evaluation of an old proble
Dermatitis 1994:31:236-41.

9 Fisher AA. Systemic contact dermatitis caused by ingestion of certain foods in propylene glycol sensitive patients. $A m \mathcal{F}$ Contact Dermat 1996;7:259.

10 Skaare A, Kjaerheim V, Barkvoll P, et al. Skin reactions and irritation of four commercial toothpastes. Acta Odontol Scand 1997;55:133-6.

11 Meltzer EO, Orgel HA, Bush RK, et al. Evaluation of symptom relief, nasal airflow, nasal cytology, and acceptability of two formulations of flunisolide nasal spray in patients with

perennial allergic rhinitis. Ann Allergy 1990;64:536-40.

12 Greenbaum J, Leznoff A, Schulz J, et al. Comparative tolerability of two formulations of Rhinalar (flunisolide) nasal spray in patients

13 Goldsmith LA. Propylene glycol. Int $\mathcal{F}$ Permatol 1978;17: 703-5.

14 Peleg O, Bar-Oz B, Arad I. Coma in a premature infant associated with the transdermal absorption of propylene associated with the transdermal absorp
glycol. Acta Paediatr 1998;87:1195-6.

15 Demey HE, Daelemans RA, Verpooten GA, et al. Propylene glycol induced side effects during intravenous nitroglycerin therapy. Intensive Care Med 1988;14:221-6.

16 Yorgin PD, Theodorou AA, Al-Uzri A, et al. Propylene glycol induced proximal renal tubular cell injury. Am F Kidney Dis 1997;30:134-9.

17 Casazza JP, Song BJ, Veech RL. Short chain diol metabolism in human disease states. Trends Biochem Sci 1990;15:26-30.

$18 \mathrm{Xu}$ D, Dhillon AS, Abelmann A, et al. Alcohol-related diols cause acute insulin resistance in vivo. Metabolism 1998;47: $1180-6$.

19 Östman M. The most common chemicals in terms of number of products. Survey 1997, annual report.Stockholm, Sweden: National Legislative Inspectorate of Chemicals (Kemikalieinspektionen) 1997. (In Swedish.)

20 Chang JC, Sparks LE, Guo Z, et al. Evaluation of sink effects on VOCs from latex paint. $\mathcal{F}$ Air Waste Manag Assoc 1998; 48:953-8.

21 Knudsen HN, Kjaer UD, Nielsen PA, et al. Sensory and chemical characterization of VOC emissions from building products: impact of concentration and air velocity. Atmospheric Environment 1999;33:1217-30.

22 Wieslander G. Water based paints. Occupational exposure and some health effects [thesis]. Uppsala, Sweden: Uppsala University, 1995 .

23 Gerin M, Patrice S, Begin D, et al. A study on ethylene glycol exposure and kidney function of aircraft de-icing workers. Int Arch Occup Environ Health 1997;69:255-65.

24 Laitinen J, Liesvuori J, Savolainen H. Exposure to glycols and their renal effects in motor servicing workers. Occup Med 1995;45:259-62.

25 Spreux A, Boyer A, Baldin B, et al. Cough or asthma crisis induced by propylene glycol. Therapie 1996;51:561-2. (In French.)
26 Wyon DP. Sick buildings and the experimental approach. Environmental Technology 1992;13:313-22.

27 Wyon NM, Wyon DP. Measurement of acute response to draught in the eye. Acta Ophthalmol 1987;65:385-92.

28 Wieslander G, Norbäck D, Nordström K, et al. Nasal and ocular symptoms, tear film stability, and biomarkers in nasal lavage, in relation to building dampness and building design in hospitals. Int Arch Occup Environ Health 1999;72: 451-61.

29 Wålinder R, Norbäck D, Wieslander G, et al. Nasal patency and lavage biomarkers in relation to dust and cleaning methods in schools. Scand F Work Environ Health 1999;25: 137-43.

30 Wieslander G, Lindgren T, Norbäck D. Changes of ocular and nasal signs and symptoms of aircrew, in relation to the ban of smoking on intercontinental flights. Scand 7 Work

31 Mølhave L, Liu Z, Jörgensen AH, et al. Sensory and physiological effects of combined exposures to air temperature and volatile organic compounds. Indoor Air 1993;3:155-69.

32 Löf A, Berlin K, Edling C, et al. Experimental studies of health effects of volatile organic compounds in water-based paints Proceedings of International Conference of Occupational Health ICOH 96. Stockholm: ICOH, 1996.

33 Nihlen A, Wålinder R, Löf A, et al. Experimental exposure to methyl tertiary-butyl ether II. Acute effects in humans. to methyl tertiary-butyl ether II. Acute
Toxicol Appl Pharmacol 1998;48:281-7.

34 Kjellberg A, Landström U, Löfstedt P, et al. Estimation of noise and annoyance in working environments. Arbete Och Hälsa 1988:30.

35 Hedenström H. Selection of lung function tests and interpretation of their results [thesis]. In: Acta Universitatis Upsaliensis, Faculty of Medicine, Stockholm. Almqvist and Wixell, 1986:1-29.

36 Norbäck D, Wieslander G, Edling C. Occupational exposure to volatile organic compounds (VOC), and other air pollutants from the indoor application of water based paints. Ann Occup Hyg 1995;39:783-94.

37 Andersson K, Hallgren C, Levin J-O, et al. Chemosorption sampling and analysis of formaldehyde in air: influence of recovery during simultaneous sampling of formaldehyde, phenol, furfural, and furfuryl alcohol. Scand $f$ Work Environ Health 1981;7:282-9.

38 Norbäck D, Wieslander G, Björnsson E, et al. Eye irritation, nasal congestion, and facial skin irritation in relation to nasal congestion, and facial skin irritation in relation to emissions from newly paint
Environment 1996;5:270-9.

39 Norbäck D, Björnsson E, Janson C, et al. Asthmatic symptoms and volatile organic compounds, formaldehyde, and carbon dioxide in dwellings Occup Environ Med 1995; 52:388-95.

40 Suber RL, Deskin R, Nikiforov I, et al. Subchronic nose-only inhalation study of propylene glycol in SpragueDawley rats. Food Chem Toxicol 1989;27:573-83.

41 Wahlberg JE. Erythema-inducing effects of solvents following epicutaneous administration to man-studied by laser Doppler flowmetry. Scand F Work Environ Health 1984;10: 159-62.

42 Harris TN, Stokes Jr. Air-borne cross-infection in the case of common cold. A further study on the use of glycol vapors for air sterilization. Am ₹ Med Sci 1943;206:631-6.

43 Lundgren B, Wieslander G, Rosell L, et al. A system for hygienic evaluation of waterborne systems. Borås, Sweden: SP Rapport, 1999:6. (In Swedish with abstract in English.)

44 Beach JR, Raven J, Ingram C, et al. The effects on asthmatics of exposure to a conventional water-based and a volatile organic compound-free paint. Eur Respir F 1997:10:563-6. 5 Millqvist E. Cough provocation with capsaicin is an objective way to test sensory hyperreactivity in patients with asthma like symptoms. Allergy 2000;55:546-50.

46 Millqvist E, Bengtsson U, Löwhagen O. Provocation with perfume in the eyes induce airways symptoms in patients with sensory hyperreactivity. Allergy 1999:54:495-9. 